\title{
Usefulness of microsimulation to translate valve performance into patient outcome: Patient prognosis after aortic valve replacement with the Carpentier-Edwards supra-annular valve
}

\author{
Martijn W. A. van Geldorp, $\mathrm{MD}^{\mathrm{a}}$ W. R. Eric Jamieson, $\mathrm{MD},{ }^{\mathrm{C}}$ A. Pieter Kappetein, MD, $\mathrm{PhD},{ }^{a}$ \\ John P. A. Puvimanasinghe, MD, PhD, ${ }^{a}$ Marinus J. C. Eijkemans, PhD, ${ }^{b}$ Gary L. Grunkemeier, PhD, ${ }^{d}$ \\ Johanna J. M. Takkenberg, MD, PhD, and Ad J. J. C. Bogers, MD, PhDa
}

丹 Supplemental material is available online.
From the Departments of Cardio-thoracic Surgery ${ }^{\mathrm{a}}$ and Public Health, ${ }^{\mathrm{b}}$ Erasmus University Medical Center, Rotterdam, The Netherlands; the University of British Columbia, ${ }^{\mathrm{c}}$ Vancouver, Canada; and Providence Health System, ${ }^{\mathrm{d}}$ Portland, Ore.

Eric Jamieson reports lecture fees and grant support from Edwards Lifesciences.

Received for publication March 6, 2006; revisions received Feb 22, 2007; accepted for publication March 8, 2007.

Address for reprints: Martijn W. A. van Geldorp, MD, Department of Cardio-thoracic Surgery, Erasmus Medical Center, Room Bd 575, PO Box 2040, 3000 CA, Rotterdam, The Netherlands (E-mail: m.vangeldorp@ erasmusmc.nl).

J Thorac Cardiovasc Surg 2007;134:702-9

$0022-5223 / \$ 32.00$

Copyright (๑) 2007 by The American Association for Thoracic Surgery

doi:10.1016/j.jtcvs.2007.03.051
Objective: Numerous reports have been published documenting the results of aortic valve replacement. It is often not easy to translate these outcomes involving the condition of the valve into the actual consequences for the patient. We previously developed an alternative method to study outcome after aortic valve replacement that allows direct estimation of patient outcome after aortic valve replacement: microsimulation modeling. The goal of this article is to provide insight into microsimulation methodology and to give an overview of the advantages and disadvantages of simulation methods (in particular microsimulation) in comparison with standard methods of outcome analysis.

Methods: By using a primary dataset containing 1847 patients and 14,429 patientyears, advantages and disadvantages of standard methods of outcome analysis are discussed, and the potential role of microsimulation is illustrated by means of a step-by-step explanation of building, testing, and using such a model.

Results: Total life expectancy, event-free life expectancy, and reoperation-free life expectancy for a 65 -year-old male patient were 10.6 years, 9.2 years, and 9.8 years, respectively. Lifetime risk of reoperation due to structural valve deterioration was $13.3 \%$.

Conclusions: Microsimulation is capable of providing accurate estimates of agerelated life expectancy and lifetime risk of reoperation for patients who underwent aortic valve replacement with the Carpentier-Edwards supra-annular valve. It provides a useful tool to facilitate and optimize the choice for a specific heart valve prosthesis in a particular patient.

$\mathrm{N}$ umerous reports have been published documenting the results of aortic valve replacement (AVR) with different types of valve prostheses. In most reports, emphasis is on the performance of the various prosthetic valves, as measured by the occurrence rates of valve-related complications and their consequences, and time-to-event analyses. This is a valid approach, but it is limited by several methodologic issues, ${ }^{1}$ and it is often not easy to translate these outcomes into the actual consequences for the patient who requires AVR.

We have previously developed an alternative method to study outcome after AVR that allows direct estimation of patient outcome after AVR: microsimulation. ${ }^{2}$ This method solves most of the methodologic limitations of standard outcomes analyses but does have several limitations of its own.

The goal of this article is to provide insight into microsimulation methodology and to give an overview of the advantages and disadvantages of microsimulation 


$$
\begin{aligned}
& \text { Abbreviations and Acronyms } \\
& \begin{aligned}
\text { AVR } & =\text { aortic valve replacement } \\
\text { CE-SAV } & =\text { Carpentier-Edwards supra-annular valve } \\
\text { EFLE } & =\text { event-free life expectancy } \\
\text { KM } & =\text { Kaplan-Meier } \\
\text { LE } & =\text { life expectancy } \\
\text { SVD } & =\text { structural valve deterioration }
\end{aligned}
\end{aligned}
$$

compared with standard methods of outcome analysis. This will be done by using primary data on outcome after AVR with the Carpentier-Edwards supra-annular valve (CESAV) prosthesis from a large single center in Canada. ${ }^{3}$ The following issues will be addressed:

1. Using the primary dataset on outcome after AVR with the CE-SAV prosthesis, we will discuss the advantages and disadvantages of standard methods of outcome analysis.

2. The information from this primary dataset will then be used to estimate patient outcome with a microsimulation model, illustrating step-by-step the construction and testing of a microsimulation model and its potential advantages and disadvantages.

\section{Materials and Methods \\ Description Dataset}

For this study, a primary dataset containing 1847 AVR procedures with the CE-SAV device was used to estimate the parameters of the Weibull distributions. ${ }^{3}$ These operations were conducted from February 1982 through December 1999 at the affiliated teaching hospitals of the University of British Columbia in Canada, namely St Paul's Hospital, Vancouver General Hospital, and the Royal Columbian Hospital.

The characteristics of the complete dataset $(n=1847)$ are summarized in Table 1. To calculate the input of the microsimulation model, 85 aortic valve rereplacements were excluded, resulting in 1762 remaining primary AVRs (see Table 1 for characteristics). Details of the occurrence of valve-related events and the associated mortality of these primary AVRs are given in Table 2. Valve-related events were defined according to the Society of Thoracic Surgeons/American Association for Thoracic Surgery Guidelines for Reporting Morbidity and Mortality after Cardiac Valvular Operations, ${ }^{4}$ with 2 modifications: transient ischemic attacks were not counted as neurologic events (to avoid recall bias), and structural valve deterioration (SVD) was only included if diagnosed either at reoperation or autopsy.

Slight differences in reporting numbers of valve-related events between this article and the earlier report of essentially the same dataset $^{3}$ can be explained by the use in the present study of a subset of 1762 patients and by differences in definition of SVD.

\section{Standard Methods of Outcome Analysis}

The Kaplan-Meier (KM) and actuarial methods are commonly used time-to-event models to estimate the survival of patients after
TABLE 1. Dataset summary

\begin{tabular}{lcc}
\hline & Total dataset & $\begin{array}{c}\text { Only primary AVR } \\
\text { included }\end{array}$ \\
\hline No. of procedures & 1847 & 1762 \\
Follow-up & & \\
$\quad$ Total follow-up (patient-years) & 14,429 & 13,849 \\
Mean follow-up time (y) & 7.8 & 7.9 \\
Range (y) & $0-20.6$ & $0-20.6$ \\
Male (\%) & 69.1 & 68.7 \\
Mean age (y) & 69.0 & 69.4 \\
Operative mortality & 5.3 & 5.0 \\
Outcome & & \\
$\quad$ Valve-related morbidity* & 311 & 292 \\
Valve-related mortality & 158 & 154 \\
Valve-related reoperations & 161 & 148 \\
Valve-related events & 469 & 446 \\
\hline AVR Aotic valver replacent
\end{tabular}

$A V R$, Aortic valve replacement. *Valve-related morbidity is defined as a nonfatal valve-related event, thus including nonfatal reoperations.

AVR. The distribution of the time to death for currently alive patients is assumed to follow the pattern of those who have already died. These methods have now been extended to summarize valverelated events, such as SVD, that are not necessarily fatal. In Figure 1 the cumulative (actuarial) risk of reoperation for SVD calculated by using the KM method (the complement of cumulative freedom from reoperation for SVD) is displayed for the CE-SAV dataset. For estimating the lifetime risk of nonfatal events, the KM and actuarial methods assume noninformative censoring: they assume that the risk of dying and the risk of SVD are independent, which in fact is not true (patients with high risk of death have lower risk of SVD, and patients with low risk of death have a higher risk of having SVD at some time in their lives). The KM and actuarial methods therefore estimate the freedom from SVD by also censoring patients who have not yet experienced the event, including those who have died and will therefore never have the event. In doing so, they describe the risk of SVD for the patient based on the assumption of immortality, resulting in a higher probability of SVD than that actually had by the patient. This effect is magnified with advancing age of valve implantation and could serve to underestimate the benefits of biologic valve implantation. Therefore although the KM and actuarial methods are perfectly capable of analyzing fatal events, for describing competing events, their value is dubious because in clinical medicine the assumption of noninformative censoring can often not be guaranteed.

One of the alternate methods of summarizing complications that are not necessarily fatal, such as SVD, is the cumulative incidence or "actual" analysis. ${ }^{5,6}$ This method takes into consideration the competing risk of death, it excludes future events attributed to already deceased patients, and it therefore calculates the percentage of patients who will experience an event before they die, answering the more pertinent question of the lifetime risk of the event. ${ }^{1,7-9}$ As is shown in Figure 1, the cumulative actuarial risk of reoperation for SVD (7.0\% at 15 years) is higher than the actual patient risk of reoperation for SVD ( $4.3 \%$ at 15 years).

The guidelines for reporting morbidity and mortality after cardiac valve operations have also incorporated the actual meth- 
TABLE 2. Occurrence rates of valve-related events and the associated reoperation and mortality rates for 1762 primary AVR procedures with the CE-SAV bioprosthesis

\begin{tabular}{|c|c|c|c|c|c|c|c|}
\hline Event & Occurrence & $\begin{array}{l}\text { Linearized } \\
\text { occurrence } \\
\text { rate } \\
\end{array}$ & $\begin{array}{c}\text { No. of } \\
\text { reoperations }\end{array}$ & $\begin{array}{c}\text { Proportion } \\
\text { undergoing } \\
\text { reoperation (\%) }\end{array}$ & $\begin{array}{c}\text { No. of } \\
\text { fatalities }\end{array}$ & $\begin{array}{c}\text { Proportion } \\
\text { fatalities (\%) }\end{array}$ & $\begin{array}{l}\text { Proportion fatalities } \\
\text { if not undergoing } \\
\text { reoperation (\%) }\end{array}$ \\
\hline Hemorrhage & 72 & 0.52 & 0 & 0 & 23 & 31.9 & 31.9 \\
\hline Nonstructural dysfunction & 33 & 0.24 & 29 & 87.9 & 3 & 9.1 & 50.0 \\
\hline Prosthetic valve endocarditis & 46 & 0.33 & 17 & 37.0 & 19 & 41.3 & 62.1 \\
\hline Structural valve deterioration* & 118 & Weibull & 98 & 83.1 & $26 \dagger$ & 22.0 & 100.0 \\
\hline Thromboembolism & 155 & 1.12 & 0 & 0 & 65 & 41.9 & 41.9 \\
\hline Valve thrombosis & 4 & 0.03 & 4 & 100.0 & 0 & 0 & Not applicable \\
\hline
\end{tabular}

AVR, Aortic valve replacement; CE-SAV, Carpentier-Edwards supra-annular valve. ${ }^{*}$ Structural valve deterioration was confirmed at reoperation or autopsy. tSix patients died at reoperation for structural valve deterioration, and 20 patients did not undergo reoperation but died with structural valve deterioration confirmed at autopsy.

od. ${ }^{4}$ Except for the cumulative incidence estimation, competing risk analyses in general do have the disadvantage of assuming that the competing events are independent. However, occurrence of an event (or reintervention) might alter the subsequent survival time and alter the risk of reoccurrence of the event.

An advantage of the KM method and the cumulative incidence method is that they can be performed with standard statistical software and that they give a valid general impression of outcome in patient populations after valve replacement. However, there are several limitations to these methods. In both KM and cumulative incidence analysis, an event can only occur once in the same patient. After the occurrence of an event, the patient is excluded from the analysis. Furthermore, although the KM and cumulative incidence analyses permit any hazard function, whereas the parametric exponential method requires a constant hazard, neither of these models take into account that event risk might change over time and might change after occurrence of events.

\section{Simulation Methods}

To obtain optimal insight into outcome after valve replacement in a particular population, ideally all patients should be followed over time until everybody has died, and all events (not only the first) that took place over time should be analyzed. In real life, the former is usually not a realistic option and the latter is difficult and time-consuming to achieve by using standard methods of outcome analysis. Simulation methods offer a complementary tool to standard methods of outcome analysis by simulating the lives of virtual patients until death and taking into account all complications that might occur over time (including repeating events and changing hazards over time, with the occurrence of prior events, or both).

The two types of simulation models that have been used to model patient outcomes after AVR are the Markov state-transition model and the microsimulation model. ${ }^{2,10}$ The Markov model creates a virtual population of patients that is followed over dif-

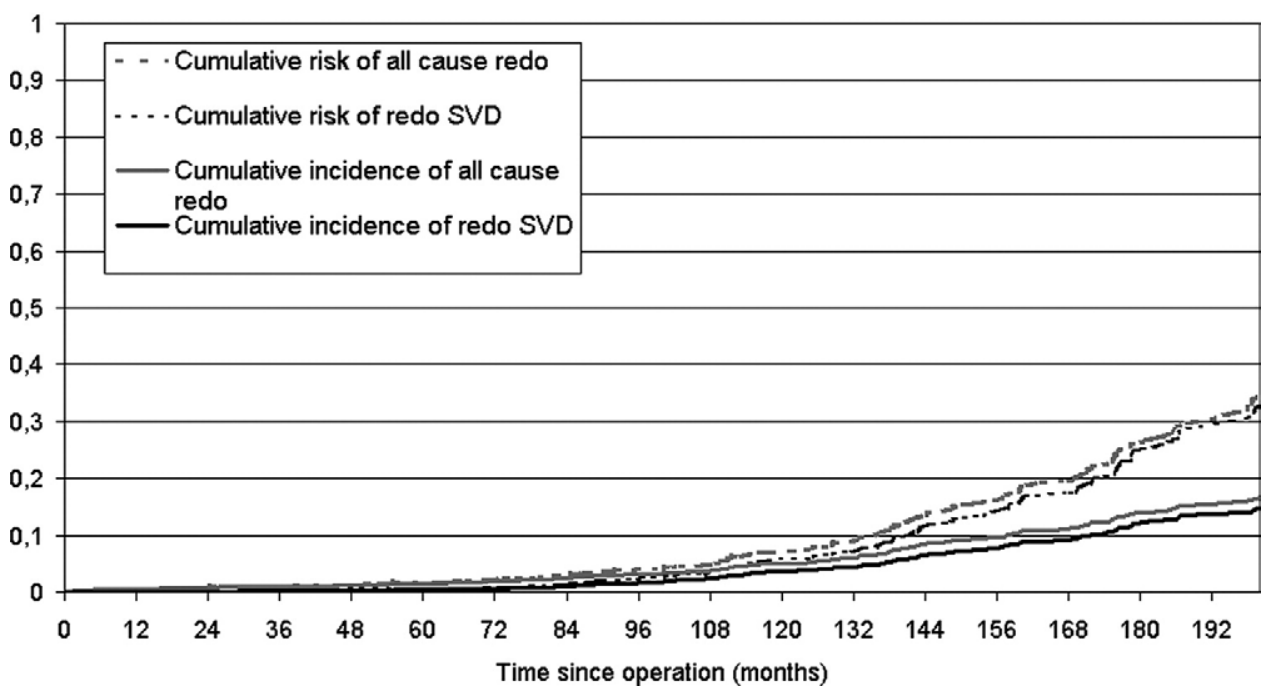

Figure 1. Cumulative incidence of reoperation and cumulative risk (equivalent of "1 minus freedom from reoperation") of all-cause reoperation and reoperation caused by structural valve deterioration (SVD) for patients in the Carpentier-Edwards supra-annular valve (CE-SAV) dataset. 
ferent time intervals until all patients have died. At each time interval, a transition from one health state to the other can occur, depending on predefined operative mortality estimates, occurrence rates of valve-related events and their consequences (death or reoperation), and the probability of dying of other non-valve related causes. Events can occur repeatedly over time, and hazards can change with each time interval, but it is hard to change hazards after the occurrence of an event by using a Markov model.

A microsimulation model is a computer model that simulates a representative population but at the level of the individual: the micro level. The remaining life (until death) of a single patient with a particular age and sex after AVR with a given valve type is simulated. It takes into account the morbidity and mortality that the patient might experience according to predefined estimates of operative mortality, event occurrence and their consequences (death or reoperation), and the probability of dying of other nonvalve related causes. By repeating this simulation multiple times (eg, 10,000 times), a virtual patient population is generated, consisting of identical patients with all possible outcomes after AVR. A detailed account of the microsimulation structure and methodology has been given previously. ${ }^{2,11}$

We used the AVR microsimulation model, designed at our institution, to provide insight into the age- and sex-related life expectancy (LE) and lifetime risks of valve-related events after AVR with the CE-SAV bioprosthesis because it has several advantages over the Markov model. First, the microsimulation model allows simulation of the individual life histories of patients, starting directly after AVR and ending with the death of the patient (follow-up does not end at the event), rather than following a virtual population over time. By simulating multiple times, the lives of identical virtual patients, all possible competing events that might occur during the remainder of life, and the time to occurrence of these events can be studied. Then, by using this virtual closed-cohort dataset, the average prognosis (including the lifetime risk of SVD and of other valve-related events) of an individual patient with these characteristics can be calculated. Furthermore, unlike the Markov model, in which time is divided in intervals during which an event might or might not occur, the microsimulation model estimates the time to the next event based on the occurrence probability of that event. Finally, the microsimulation model allows for adjustment of event occurrence rates with time or based on the occurrence of prior events (eg, operative mortality increases with age and with each successive reoperation).

\section{Building a Microsimulation Model}

Figure 2 shows the general structure of the microsimulation model, including and itemizing the information that is needed to start building the model.

Operative mortality estimates. To obtain accurate (and agerelated) estimations of operative mortality after AVR, these parameters were estimated by using data derived from an earlier meta-analysis containing 5837 patients with a total follow-up of 31,874 patient-years. ${ }^{11}$ Operative mortality was estimated as $2.6 \%$ for a 40-year-old man, increasing with an odds ratio of 1.034 for age (per year). For a 69-year-old man, operative mortality would be $6.6 \%$. The real operative mortality derived from the CE-SAV dataset for primary AVR (mean age 69 years) was 5.0\%.

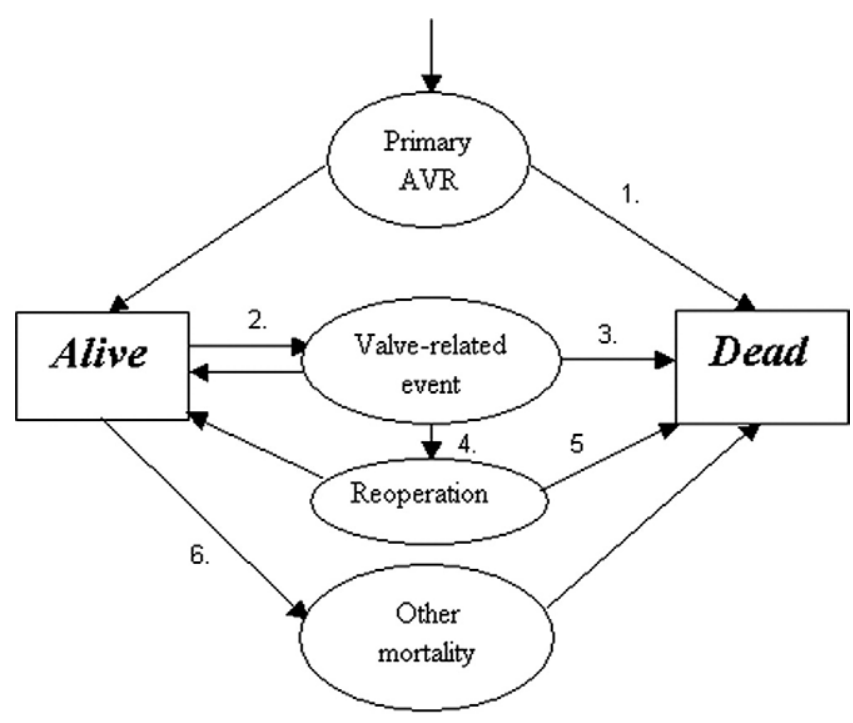

1. Operative mortality estimates

2. Estimates occurrence rates of valve related events

3. Mortality risk associated with each valve-related event

4. Reoperation risk associated with each valve-related event

5. Mortality risk associated with each reoperation

6. Estimate of mortality risk due to other causes

Figure 2. General structure of the microsimulation model. AVR, Aortic valve replacement.

Estimates of occurrence rates of valve-related events. The estimates of occurrence rates of valve-related events are derived from the primary dataset described earlier (patients with primary AVR only) and are depicted in Table 2. Assuming a constant hazard over time, weighted mean estimates of linearized annual occurrence rates were calculated for valve thrombosis, thromboembolism, endocarditis, and nonstructural dysfunction, respectively. The occurrence of hemorrhage was modeled as an agedependent hazard of 0.076 , with an age-dependent mortality of $0.034 .^{12}$

A reoperation because of SVD is more relevant to the patient than the occurrence of SVD without consequences. ${ }^{7}$ Furthermore, the onset and severity of SVD is difficult to measure. Hence SVD was defined as "reoperation caused by SVD" or "SVD confirmed by means of autopsy." The cumulative risk of SVD in a bioprosthesis decreases with increasing age of the patient at valve implantation and increases subexponentially with elapsing time since implantation. ${ }^{13}$ Grunkemeier and colleagues ${ }^{14}$ have shown that the Weibull distribution, a generalization of the exponential distribution, was efficient in summarizing SVD in biologic valves. ${ }^{15}$ However, they stressed that at least 12 years of follow-up are needed to provide reliable estimates. ${ }^{14} \mathrm{We}$ used primary data on the CE-SAV bioprosthesis, with a 20-year follow-up, as described in the previous section, to calculate the parameters of the Weibull distributions. ${ }^{3}$ The value of the scale $(\sigma)$ parameter of the Weibull model, fitted to represent SVD depends on age: $\sigma+$ $e^{2.2240+0.0154 * A g e}$. The shape parameter $(\beta)$ was estimated at 3.316. With the resulting age-dependent Weibull distributions for 
reoperation caused by SVD, median time to reoperation caused by SVD in the supra-annular valves was 19.2 (range 18.0-20.5), 22.4 (range 20.5-24.6), and 26.2 years (range 23.1-29.7), respectively for 55-, 65-, and 75-year-old male patients.

Mortality risk associated with each valve-related event. The estimates of mortality risk associated with each valve-related event are derived from the primary dataset described earlier and are depicted in Table 2.

Reoperation risk associated with each valve-related event. The estimates of reoperation risk associated with each valverelated event are derived from the primary dataset described earlier and are depicted in Table 2.

Mortality risk associated with each reoperation. The estimates of reoperative mortality risk were also obtained from the previous meta-analysis discussed above. ${ }^{11}$ For each first and following reoperation in a single patient, the operative mortality of $1.5 \%$ was increased, with an odds ratio of 1.7 . The mean age of the patients undergoing reoperation in the CE-SAV dataset was 53 years, and therefore the expected reoperative mortality in the dataset would be as follows: $2.7 \%+1.034^{(53-40)}+1.7=5.9 \%$. Again, this reoperative mortality was comparable with the observed reoperative mortality in the CE-SAV dataset, which was $5.4 \%$.

Estimate of mortality risk caused by other factors (mortality risk of general population plus excess mortality). The mortality of a patient after valve replacement is composed of the mortality of the general population, the operative mortality, the valve-related mortality, and an excess mortality. This excess mortality cannot be explained by valve-related events but is due to mortality associated with underlying valve pathology, left ventricular function, increased occurrence of sudden unexpected unexplained death, and the underreporting of valve-related events, respectively. ${ }^{16-18}$ The model calculates patient outcomes by superimposing the morbidity and mortality estimates of valve-related events on the other components of patient mortality.

The mortality of the general population was incorporated into the model by means of the life table of the relevant age- and sex-matched population, American male subjects in this analysis. ${ }^{19}$ The excess mortality, not accounted for by the valve-related events, was represented by age- and sex-specific hazard ratios. These hazard ratios have previously been estimated by approximating age- and sex-specific survival curves produced by the model, which contained background morbidity and mortality caused by valve-related events to the corresponding empiric curves obtained from data on stented porcine bioprostheses that contained all 3 components of patient mortality. ${ }^{20,21}$ The hazard ratios were $2.9,1.8,1.2$, and 0.8 for male patients aged $45,55,65$, and 75 years, respectively. ${ }^{16}$ The LE of a 65 -year-old patient, for example, was estimated at 10.6 years. This corresponds to a 10 -year survival of $50 \%$, which is comparable with survival in other reports. ${ }^{22-24}$ However, it is in contrast to an LE of 13.8 years for a 65-year-old male patient in the relevant general population, which translates to a $78 \%$ relative LE for the patient. The relative LE of a 65-year-old hypothetical patient who is immune from valve-related events and from operative mortality was about $90 \%$. In the latter instance, the excess mortality of the patient might be related to underlying valve pathology, left ventricular residual hypertrophy, and functional abnormality.

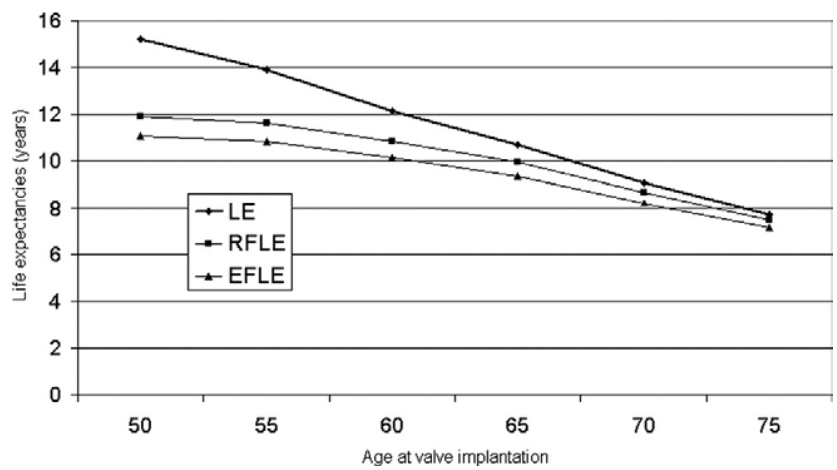

Figure 3. Life expectancy (LE), event-free life expectancy (EFLE), and reoperation-free life expectancy (RFLE) for men at different ages of valve implantation.

Kvidal and colleagues, ${ }^{17}$ who investigated this excess mortality after heart valve replacement, described an increasing excess hazard during follow-up and a decreasing excess hazard with advancing age of implantation. This supports a "multiplicative" excess mortality, which was a structural assumption in our model. The use of an "additive" model might overestimate LE estimates, especially in patients younger than 70 years.

\section{Results}

\section{Running a Microsimulation Model}

By repeatedly simulating individual life histories of male patients aged 55, 65, and 75 years a total of 10,000 times, the microsimulation model calculated actuarial patient survival, reoperation-free survival, and event-free survival of male patients of different ages at valve implantation. The areas under the respective curves represent $\mathrm{LE}$, reoperation-free $\mathrm{LE}$, and event-free life expectancy (EFLE). LE, reoperation-free LE, and EFLE for men at different ages of valve implantation are given in Figure 3.

The microsimulation model also calculated the actual or lifetime risks of valve-related events and SVD after valve implantation. The risk of SVD reduced with advancing age of implantation, namely $31.8 \%, 13.3 \%$, and $3.6 \%$, respectively, for 55-, 65-, and 75-year-old male subjects. The lifetime risk of having at least 1 event also decreased with increasing implantation age.

\section{Testing a Microsimulation Model}

Validation. There are 2 types of validation: internal and external validation. Internal validation tests whether the results of the microsimulation model correspond to the outcome in the dataset from which the model was derived. For example, observed survival in the CE-SAV dataset was $27 \%$ at 15 years, whereas this was $21 \%$ by using the microsimulation model for a 69-year-old patient (mean age of the CE-SAV population). Furthermore, observed actual freedom from all-cause reoperation in the dataset was $86 \%$ 
TABLE 3. Summary of sensitivity analysis for a 65-year-old male patient after AVR with the CE-SAV

\begin{tabular}{|c|c|c|c|c|c|c|c|c|c|}
\hline \multirow[b]{2}{*}{ Parameter } & \multirow{2}{*}{$\begin{array}{l}\text { Baseline } \\
\text { estimate }\end{array}$} & \multicolumn{2}{|c|}{ Plausible range* } & \multicolumn{2}{|c|}{ Life expectancy (y) } & \multicolumn{2}{|c|}{$\begin{array}{l}\text { Event-free life } \\
\text { expectancy (y) }\end{array}$} & \multicolumn{2}{|c|}{$\begin{array}{c}\text { Reoperation-free life } \\
\text { expectancy (y) }\end{array}$} \\
\hline & & Favorable & Unfavorable & Favorable & Unfavorable & Favorable & Unfavorable & Favorable & Unfavorable \\
\hline Hemorrhage & 0.52 & 0.39 & 0.65 & 10.7 & 10.4 & 9.3 & 9.1 & 9.9 & 9.8 \\
\hline Nonstructural dysfunction & 0.24 & 0.18 & 0.30 & 10.6 & 10.6 & 9.3 & 9.2 & 9.9 & 9.8 \\
\hline Prosthetic valve endocarditis & 0.33 & 0.25 & 0.42 & 10.6 & 10.5 & 9.3 & 9.2 & 9.9 & 9.8 \\
\hline Structural valve deteriorationt & 22.4 & 28.0 & 16.8 & 10.8 & 10.6 & 9.7 & 8.7 & 10.3 & 9.2 \\
\hline Thromboembolism & 1.12 & 0.84 & 1.40 & 10.7 & 10.5 & 9.4 & 9.1 & 9.9 & 9.7 \\
\hline Valve thrombosis & 0.03 & 0.02 & 0.04 & 10.6 & 10.6 & 9.2 & 9.2 & 9.8 & 9.8 \\
\hline Excess mortality (hazard ratio) & 1.2 & 0.9 & 1.5 & 12.0 & 9.5 & 10.2 & 8.4 & 10.9 & 9.0 \\
\hline
\end{tabular}

$A V R$, Aortic valve replacement; CE-SAV, Carpentier-Edwards supra-annular valve. *The baseline estimates were increased and decreased by $25 \%$ to estimate the plausible range. †Median time to reoperation caused by structural valve deterioration.

at 15 years, whereas this was $82 \%$ for a 69 -year-old patient by using microsimulation.

External validation tests whether a model also performs satisfactorily for patients other than the ones from whose data the model was derived. Figure E1 displays the age- and sex-specific survival results of the model with corresponding survival curves for the Carpentier-Edwards standard bioprosthesis (Edwards Lifesciences LLC, Irvine, Calif). This dataset was obtained from the Providence Health System in Portland, Oregon. ${ }^{25}$ The survival outputs of the microsimulation model for 55- and 65-year-old male patients compared favorably with the corresponding curves of the Carpentier-Edwards standard Portland experience through 25 years after implantation: the 10year-survival of a 55- and 65-year-old male patient was, respectively, $64 \%$ and $50 \%$ in the model versus $65 \%$ and $53 \%$ in the Portland dataset. However, the model showed a slight overestimation of mortality for 75-year-old male subjects compared with the Portland dataset: the 10-yearsurvival was $32 \%$ in the model versus $40 \%$ in the Portland dataset. Patients who undergo an operation in this age group do not strictly represent the average patient in this age group who actually requires AVR. In fact, they represent a selection of relatively healthier patients with a relatively better LE. Systematic variations in the patient profile, too, especially in the older age groups, might result in these differences between model output and comparison data.

Sensitivity analysis. The effect of uncertainty in the parameter estimates of the model, such as variability across subgroups, can be investigated by means of sensitivity analysis. In one-way sensitivity analysis the value of one probability is varied, whereas others are kept constant to test the stability of the analysis' conclusions and to test whether the outcome might change, depending on the characteristics of the subgroup. ${ }^{26}$ It ignores interactions between different parameters and can therefore underestimate the level of uncertainty. Multivariate sensitivity analysis would be pre- ferred, but then also the distributions of the parameters have to be known, which in our study is not yet possible. For this reason, we performed one-way sensitivity analysis, and variation of the estimates by their $95 \%$ confidence intervals yielded only very small changes in the long-term outcomes. Therefore we defined larger ranges by increasing and decreasing the baseline estimates by $25 \%$. The resulting LE and EFLE of a 65-year-old male patient for a plausible range of valve-related events and additional mortality is given in Table 3. It shows that variation in the hazard ratio representing excess mortality had the most pronounced effect on both LE and EFLE, and it underscores the importance of the excess mortality on the outcomes of patients after AVR.

\section{Discussion}

Microsimulation has several important limitations. First, microsimulation is a simplification of reality, just like any other model. Adding more variables will result in more patient-specific outcome estimates and will bring the model closer to reality. We intend to study the effect of parameters such as left ventricular function, cardiac rhythm, and renal function. However, it is very difficult to derive the necessary data from published studies: more high-quality primary datasets are needed for this refinement of the microsimulation model. In addition, currently, the microsimulation model uses point estimates of the occurrence rates of valverelated events, ignoring the variation in these estimates. We are currently developing a new extension of the microsimulation model that allows entering not only point estimates of the occurrence rates of valve-related events but also the distribution of these estimates. Furthermore, in the model we assume (by definition) all patients with SVD either have a reoperation or die, whereas in reality a proportion of patients with SVD, particularly the elderly, will not receive a reoperation and will die of other causes. Therefore, the model will slightly overestimate the risk of reoperation for SVD, especially in the higher age group. 
Second, the current simulation model is based on certain structural assumptions regarding mortality and morbidity after AVR. For example, a constant hazard was assumed for the valve-related events other than SVD. Certain hazards of complications, such as hazard of bleeding, will not be constant over time but will increase with advancing age or have a high-risk and a lower-risk phase, such as endocarditis. Therefore, in our model there is an age-dependent risk and age-dependent mortality for "bleeding." The model does not have a 2-period risk for endocarditis because we do not have access yet to primary datasets to support these changing hazards over time. Furthermore, sudden unexpected unexplained death is incorporated in the excess mortality because gaining insight into this determinant remains difficult. $^{27}$

The third limitation is the fact that the quality of the model, as in any model, is directly dependent on the quality of the input. Especially for input in simulation models, high-quality data are essential. Most of the model input is obtained from meta-analysis of earlier published studies, largely with a retrospective design, which are generally known to underestimate the incidence of (valve-related) events. Furthermore, heterogeneity between the studies and possible publication bias can diminish the quality of the model input.

Finally, another disadvantage is the fact that the microsimulation software is not yet available in standard statistical software packages. However, the computer program, along with an extensive manual to get started with microsimulation, is available at www.cardiothoracicresearch.nl.

\section{Conclusions}

This study aimed to provide insight into microsimulation methodology and to give an overview of the advantages and disadvantages of simulation methods (in particular microsimulation) in comparison with standard methods of outcome analysis. It showed, using a large existing dataset, ${ }^{3}$ that microsimulation is capable of translating valve performance into patient outcome by providing age-related LE and risk of reoperation for patients who underwent AVR with the CE-SAV bioprosthesis. These estimates of patient outcome might be used to compare the patient lifetime risk of reoperation with the CE-SAV bioprosthesis with the pericardial valves and with newer bioprostheses in a comparable patient population.

This study also showed that microsimulation has several disadvantages and limitations that need to be considered carefully and dealt with systematically when attempting to perform simulation studies.

In conclusion, microsimulation can be a quick, accurate, and useful tool to assess patient outcome after AVR with a specific prosthetic heart valve. Outcomes after implantation of different prosthetic heart valves can easily be compared to facilitate and optimize the choice of specific heart valve prostheses for both physician and patient.

\section{References}

1. Grunkemeier GL, Wu Y. Interpretation of nonfatal events after cardiac surgery: actual versus actuarial reporting. J Thorac Cardiovasc Surg. 2001;122:216-9.

2. Takkenberg JJ, Puvimanasinghe JP, Grunkemeier GL. Simulation models to predict outcome after aortic valve replacement. Ann Thorac Surg. 2003;75:1372-6.

3. Jamieson WR, Burr LH, Miyagishima RT, Germann E, Macnab JS, Stanford E, et al. Carpentier-Edwards supra-annular aortic porcine bioprosthesis: clinical performance over 20 years. J Thorac Cardiovasc Surg. 2005;130:994-1000.

4. Edmunds LH Jr, Clark RE, Cohn LH, Grunkemeier GL, Miller DC, Weisel RD. Guidelines for reporting morbidity and mortality after cardiac valvular operations. Ad Hoc Liaison Committee for Standardizing Definitions of Prosthetic Heart Valve Morbidity of The American Association for Thoracic Surgery and The Society of Thoracic Surgeons. J Thorac Cardiovasc Surg. 1996;112:708-11.

5. Grunkemeier GL, Anderson RP, Miller DC, Starr A. Time-related analysis of nonfatal heart valve complications: cumulative incidence (actual) versus Kaplan-Meier (actuarial). Circulation. 1997;96(suppl): II70-5.

6. Grunkemeier GL, Jamieson WR, Miller DC, Starr A. Actuarial versus actual risk of porcine structural valve deterioration. J Thorac Cardiovasc Surg. 1994;108:709-18.

7. Kaempchen S, Guenther T, Toschke M, Grunkemeier GL, Wottke M, Lange R. Assessing the benefit of biological valve prostheses: cumulative incidence (actual) vs. Kaplan-Meier (actuarial) analysis. Eur J Cardiothorac Surg. 2003;23:710-4.

8. Jamieson WR, Burr LH, Miyagishima RT, Germann E, Anderson WN. Actuarial versus actual freedom from structural valve deterioration with the Carpentier-Edwards porcine bioprostheses. Can J Cardiol. 1999;15:973-8.

9. Grunkemeier GL, Wu Y. Actual versus actuarial event-free percentages. Ann Thorac Surg. 2001;72:677-8.

10. Birkmeyer NJ, Birkmeyer JD, Tosteson AN, Grunkemeier GL, Marrin CA, O'Connor GT. Prosthetic valve type for patients undergoing aortic valve replacement: a decision analysis. Ann Thorac Surg. 2000;70: 1946-52.

11. Puvimanasinghe JP, Steyerberg EW, Takkenberg JJ, Eijkemans MJ, van Herwerden LA, Bogers AJ, et al. Prognosis after aortic valve replacement with a bioprosthesis: predictions based on meta-analysis and microsimulation. Circulation. 2001;103:1535-41.

12. van der Meer FJ, Rosendaal FR, Vandenbroucke JP, Briet E. Assessment of a bleeding risk index in two cohorts of patients treated with oral anticoagulants. Thromb Haemost. 1996;76:12-6.

13. Jamieson WR, Rosado LJ, Munro AI, Gerein AN, Burr LH, Miyagishima RT, et al. Carpentier-Edwards standard porcine bioprosthesis: primary tissue failure (structural valve deterioration) by age groups. Ann Thorac Surg. 1988;46:155-62.

14. Grunkemeier GL, Li HH, Naftel DC, Starr A, Rahimtoola SH. Longterm performance of heart valve prostheses. Curr Probl Cardiol. 2000;25:73-154.

15. Thoman DR, Bain LJ, Antle CE. Influences on the parameters of the Weibull distribution. Technometrics. 1969;11:445-60.

16. Steyerberg EW, Kallewaard M, van der Graaf Y, van Herwerden LA, Habbema JD. Decision analyses for prophylactic replacement of the Bjork-Shiley convexo-concave heart valve: an evaluation of assumptions and estimates. Med Decis Making. 2000;20:20-32.

17. Kvidal P, Bergstrom R, Horte LG, Stahle E. Observed and relative survival after aortic valve replacement. J Am Coll Cardiol. 2000;35: 747-56.

18. Blackstone E. The choice of a prosthetic heart valve: how shall patient-specific recommendations be made? J Heart Valve Dis. 19987 $1-3$. 
19. Available at: www.cdc.gov. Vital statistics of the US 1992, Centers for Disease Control and Prevention and the National Center for Health Statistics.

20. Fann JI, Miller DC, Moore KA, Mitchell RS, Oyer PE, Stinson EB, et al. Twenty-year clinical experience with porcine bioprostheses. Ann Thorac Surg. 1996;62:1301-12.

21. Puvimanasinghe JP, Takkenberg JJ, Edwards MB, Eijkemans MJ, Steyerberg EW, Van Herwerden LA, et al. Comparison of outcomes after aortic valve replacement with a mechanical valve or a bioprosthesis using microsimulation. Heart. 2004;90:1172-8.

22. Jamieson WR, Ling H, Burr LH, Fradet GJ, Miyagishima RT, Janusz MT, et al. Carpentier-Edwards supraannular porcine bioprosthesis evaluation over 15 years. Ann Thorac Surg. 1998;66(suppl):S49-52.

23. Jamieson WR, Janusz MT, Burr LH, Ling H, Miyagishima RT, Germann E. Carpentier-Edwards supraannular porcine bioprosthesis: second- generation prosthesis in aortic valve replacement. Ann Thorac Surg. 2001;71(suppl):S224-7.

24. Corbineau H, De La Tour B, Verhoye JP, Langanay T, Lelong B, Leguerrier A. Carpentier-Edwards supraannular porcine bioprosthesis in aortic position: 16-year experience. Ann Thorac Surg. 2001; 71(suppl):S228-31.

25. Gao G, Wu Y, Grunkemeier GL, Furnary AP, Starr A. Durability of pericardial versus porcine aortic valves. J Am Coll Cardiol. 2004;44:384-8.

26. Hunink MG, Glasziou PP, Siegel JE, Weeks JC, Pliskin JS, Elstein AS, Weinstein MC. Decision making in health and medicine. Integrating the evidence and values. Cambridge: Cambridge University Press; 2001.

27. Lauer MS, Blackstone EH, Young JB, Topol EJ. Cause of death in clinical research: time for a reassessment? J Am Coll Cardiol. 1999; 34:618-20. 
Calculated survival (model) versus observed survival (Portland)

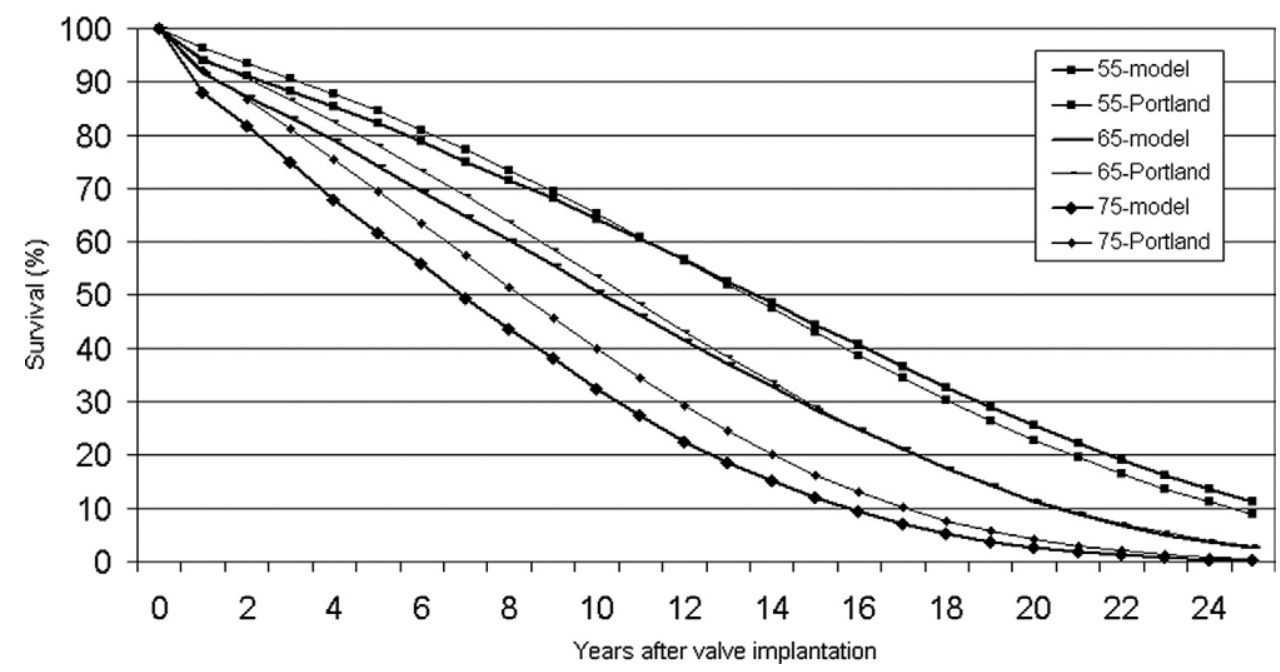

Figure E1. External validation: microsimulation-calculated survival compared with observed survival (Portland dataset). 